\title{
Cathodoluminescence characterization of Ge-doped CdTe crystals
}

\author{
U. Pal, P. Fernández, and J. Piqueras \\ Departamento de Física de Materiales, Facultad de Ciencias Físicas, Universidad Complutense, \\ 28040 Madrid, Spain \\ N. V. Sochinskii \\ Departamento de Física de Materiales, Universidad Autónoma, 28040 Madrid, Spain and Institute of \\ Semiconductor Physics, Pr. Nauki 45, 252650 Kiev, Ukraine and New Semiconductor Inc., P. O. Box 222, \\ 254210 Kiev, Ukraine \\ E. Diéguez \\ Departamento de Física de Materiales, Universidad Autónoma, 28040 Madrid, Spain
}

(Received 8 December 1994; accepted for publication 11 April 1995)

Cathodoluminescence (CL) microscopic techniques have been used to study the spatial distribution of structural defects and the deep levels in CdTe:Ge bulk crystals. The effect of Ge doping with concentrations of $10^{17}$ and $10^{19} \mathrm{~cm}^{-3}$ on the compensation of $V_{\mathrm{Cr}}$ in CdTe has been investigated. Dependence of the intensity distribution of $\mathrm{CL}$ emission bands on the dopant concentration has been studied. Ge doping causes a substantial reduction of the generally referred to $1.40 \mathrm{eV}$ luminescence, which is often present in undoped CdTe crystals, and enhances the 0.91 and $0.81 \mathrm{eV}$ emissions. (C) 1995 American Institute of Physics.

\section{INTRODUCTION}

Recently, the doped CdTe bulk crystals have shown great promise for infrared optical processing application. ${ }^{1,2}$ The perspective of their practical usage puts forward several requirements to the crystals. In particular, a high roomtemperature resistivity and a good photoconductivity on infrared irradiation are needed.

There exist few possibilities to get the CdTe crystals with the desirable properties by doping. These possibilities base themselves on the fact that in the undoped CdTe the main residual point defects are the shallow acceptors such as the background impurities of the group $1(\mathrm{Li}, \mathrm{Na}, \mathrm{Cu}, \mathrm{Ag})$ and their complexes with the native defects, mainly the vacancies of cadmium $\left.\left(V_{\mathrm{Cd}}\right)\right)^{3,4}$ For example, high-resistivity CdTe could be obtained by compensative doping with chlorine or gallium which are shallow donors in Te or Cd sublattices, respectively. ${ }^{3,5}$ However, doping with the impurities of $\mathrm{V}$ or IV groups, e.g., vanadium or germanium, can also provide the semi-insulating CdTe crystals by compensating deep donor levels. ${ }^{1,6}$

It was demonstrated for the CdTe: $V$ crystals by electronparamagnetic-rcsonance (EPR) studies that the $\mathrm{V}$ impurity incorporates as an electrically and optically active defect into $\mathrm{Cd}$ sites, introducing a deep donor level at $E_{V}+0.80 \mathrm{eV}{ }^{7}$ Recently, we have shown the drastic changes of CdTe Iuminescent properties related with $\mathrm{V}$ doping. ${ }^{8}$ Regarding to the Ge doping, which has some technological advantages, the Ge-related electronic levels have been studied by a few experimental methods such as photoconductivity, ${ }^{1,9}$ thermally stimulated conductivity, ${ }^{6}$ and the constant photocurrent method. ${ }^{10}$ Neverthelcss, to our knowledge, there is no information about the influence of $\mathrm{Ge}$ doping on the luminescence properties of CdTe.

In the present investigation, semi-insulating CdTe:Ge with different Ge contents has been studied by cathodoluminescence (CL) with a scanning electron microscope. Differ- ent emissions are correlated either to Ge dopant or to other defect centers. CL images are recorded to study the defect distribution in the crystals. The effect of thermal annealing on the evolution of CL bands is studied. The CL bands revealed in the $1.10-0.78 \mathrm{eV}$ region are compared with the results of undoped samples in the same region.

\section{EXPERIMENT}

The CdTe bulk crystals used in the present investigation were grown by the vertical Bridgman technique at the experimental conditions specified elsewhere. ${ }^{4}$ The doping was done by introducing high-purity $\mathrm{Ge}$ into the ampoule. The calculated Ge concentrations in CdTe crystals were $10^{17}$ and $10^{19} \mathrm{~cm}^{-3}$. Hereafter, we will call these crystals CdTe:Ge1 and CdTe:Ge2, respectively. The resistivity of both types of $\mathrm{CdTe}: \mathrm{Ge}$ crystals was $10^{8}-10^{9} \Omega \mathrm{cm}$ at room temperature.

The monocrystalline wafers of about $20 \times 10 \times 1 \mathrm{~mm}^{3}$ were cut from the central part of the grown crystals and polished by alumina powders, followed by a chemomechanical polishing with $\mathrm{Br}_{2}(2 \mathrm{vol} \%)$-methanol solution. Some of the as-grown wafers were annealed at $600^{\circ} \mathrm{C}$ for $5 \mathrm{~h}$ under an $\mathrm{Ar}$ flux. To avoid annealing induced surface defects, the annealed wafers were polished again to remove about $50 \mu \mathrm{m}$ from the surfaces.

The wafers were sliced and the samples obtained were observed in a Hitachi S-2500 scanning electron microscope in the emissive and $\mathrm{CL}$ modes at temperatures between 80 and $300 \mathrm{~K}$ with an accelerating voltage of $25 \mathrm{kV}$. The experimental setup for spectral and panchromatic $\mathrm{CL}$ measurements with a North Coast EO-817 germanium detector has been described elsewhere. ${ }^{11}$ In order to separate the contributions of the different bands in the CL images, monochromatic CL images are recorded at fixed wavelengths corresponding to the peak positions in the CL spectra. Spectra are recorded under different focusing conditions of the electron beam on the samples to account for the radiative centers with 


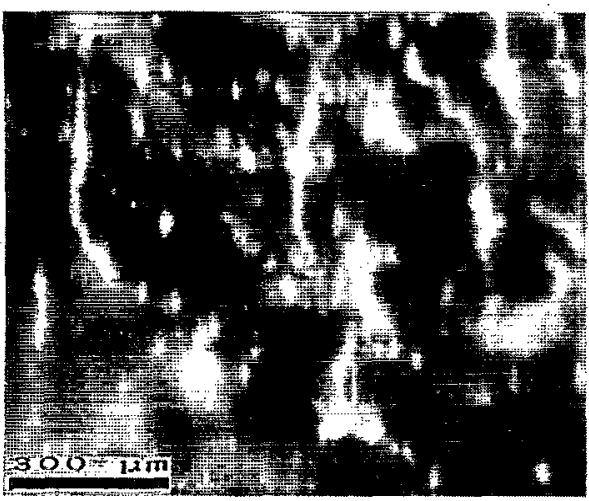

FIG. 1. Panchromatic CL image of as-grown CdTe:Ge1.

low concentrations. ${ }^{12,13}$ Usually by defocusing, the intensity of deep level bands increases. In the following description, spectra showing deep level emissions have been recorded with a defocused electron beam.

\section{RESULT}

Figure 1 shows a typical panchromatic CL image of the as-grown $\mathrm{CdTe}: \mathrm{Ge} 1$ sample. Bright sub-boundaries with a certain structure and bright spots inside the subgrains are revealed. Similar images were also observed in case of our previously studied CdTe:V samples. ${ }^{8}$ The CL spectrum of CdTe:Gel samples at $80 \mathrm{~K}$ obtained under defocusing conditions is given in Fig. 2(a). Neither the band-edge peak nor the generally referred to $1.40 \mathrm{eV}$ peak were clearly revealed. However, those two bands were revealed, though with a very low intensity, in the as-grown CdTe:Ge2 samples by defocusing the electron beam [Fig. 2(b)]. Also, an intense band at about $0.91 \mathrm{eV}$ and a very weak band near $1.08 \mathrm{eV}$ appeared along with the $0.81 \mathrm{eV}$ band. It is observed in Fig. 2 that the $0.81 \mathrm{eV}$ band appears more intense in the sample with a higher $\mathrm{Ge}$ concentration. Under the focused electron-beam condition, in all the doped samples, the total CL intensity was low and only a peak near $0.81 \mathrm{eV}$ was revealed.

Figure 3 shows the CL spectra of the CdTe:Ge;samples after annealing. No band-edge peak or the $1.40 \mathrm{eV}$ peak appeared under any of the electron-beam conditions. However, both the 0.91 and $0.81 \mathrm{eV}$ bands appeared under both electron-beam conditions. There are at least four bands in the $0.72-1.10 \mathrm{eV}$ energy range, with at least two sub-bands each, which have often been detected in CdTe crystals by other workers ${ }^{14,15}$ in their photoluminescence studies. From the shape of the $0.91 \mathrm{eV}$ band in our CL spectra, it appears that the band has a complex structure. In some cases, the $0.78 \mathrm{eV}$ band was resolved from the $0.81 \mathrm{eV}$ band. In the annealed samples the intensity of the $0.81 \mathrm{eV}$ band increases with $\mathrm{Ge}$ concentration (Fig. 3), which is a similar behavior to that found in the as-grown samples. Figure 4 shows the panchromatic CL image of an annealed CdTe:Gel sample at 80 $\mathrm{K}$. By annealing, the sharper sub-boundaries become blurred and the contrast is drastically reduced. Monochromatic inages recorded with the monochromator slit at 0.90 or $0.80 \mathrm{eV}$ exhibit the same general luminescence distribution as that shown in Fig. 4. The general appearance of the image from
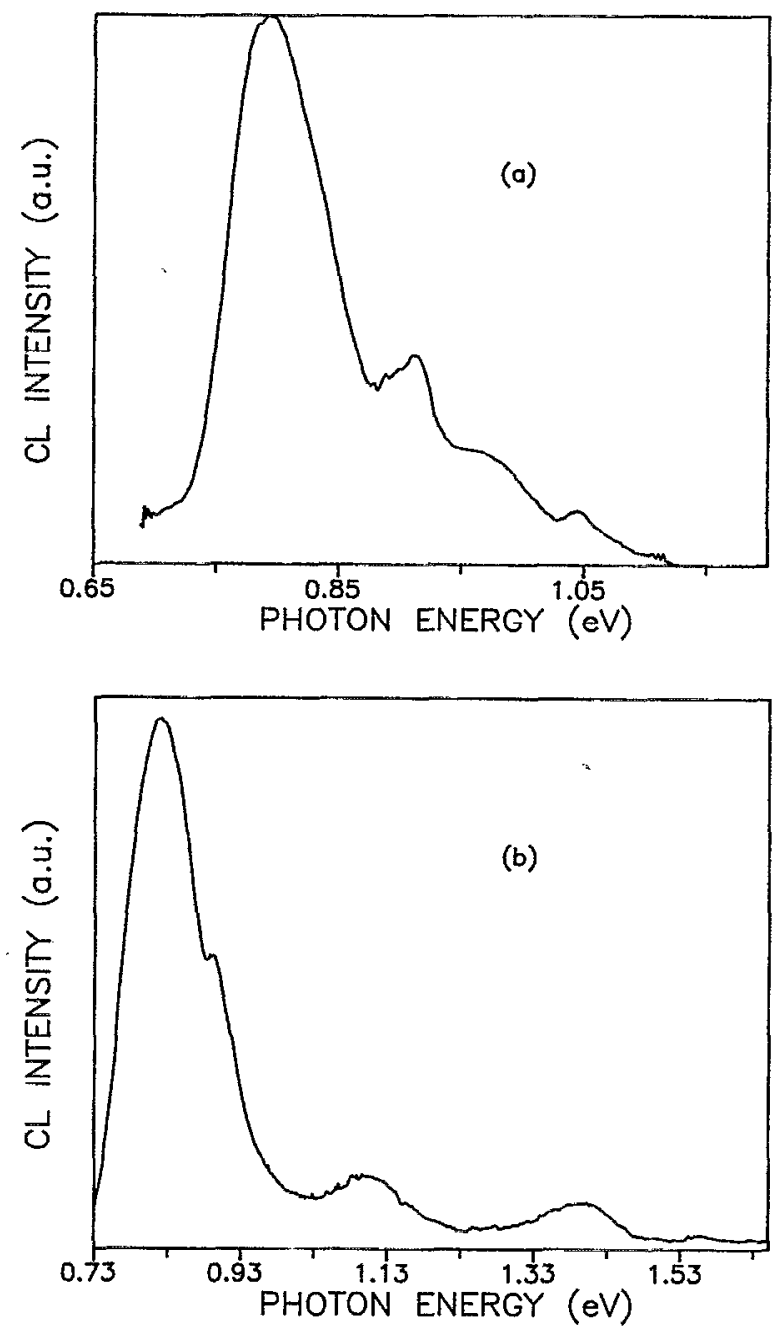

FIG. 2. CL spectra recorded under defocusing conditions of as-grown samples: (a) CdTe:Ge1 and (b) CdTe:Ge2.

the as-grown CdTe:Ge2 sample is very similar to the image of the CdTe:Gel sample, but in this case the subgrain boundaries are more continuous and subgrain size is reduced (Fig. 5). After annealing, the general features in $\mathrm{CL}$ images of CdTe:Ge2 are very similar to the annealed CdTe:Ge1 samples. CL spectra of undoped untreated CdTe samples show $^{8}$ near band-edge emission and the $1.40 \mathrm{eV}$ band not observed in CdTe:Ge. The undoped samples after the same annealing treatment given to the Ge-doped samples show an intense band at $1.08 \mathrm{eV}$. CL images of undoped samples show a well defined subgrain structure which is not modified by annealing. ${ }^{8,13}$

\section{DISCUSSION}

Undoped samples show near band-edge emission as well as a band at $1.40 \mathrm{eV}$ while both bands are generally absent in Ge-doped samples. The $1.40 \mathrm{eV}$ band in CdTe has a complex nature with a component, which in some cases determines the appearance of the band, due to $A$ centers (cadmium vacancy-donor pairs). This component explains the absence or reduction of $1.40 \mathrm{eV}$ emission in Ge-doped samples be- 

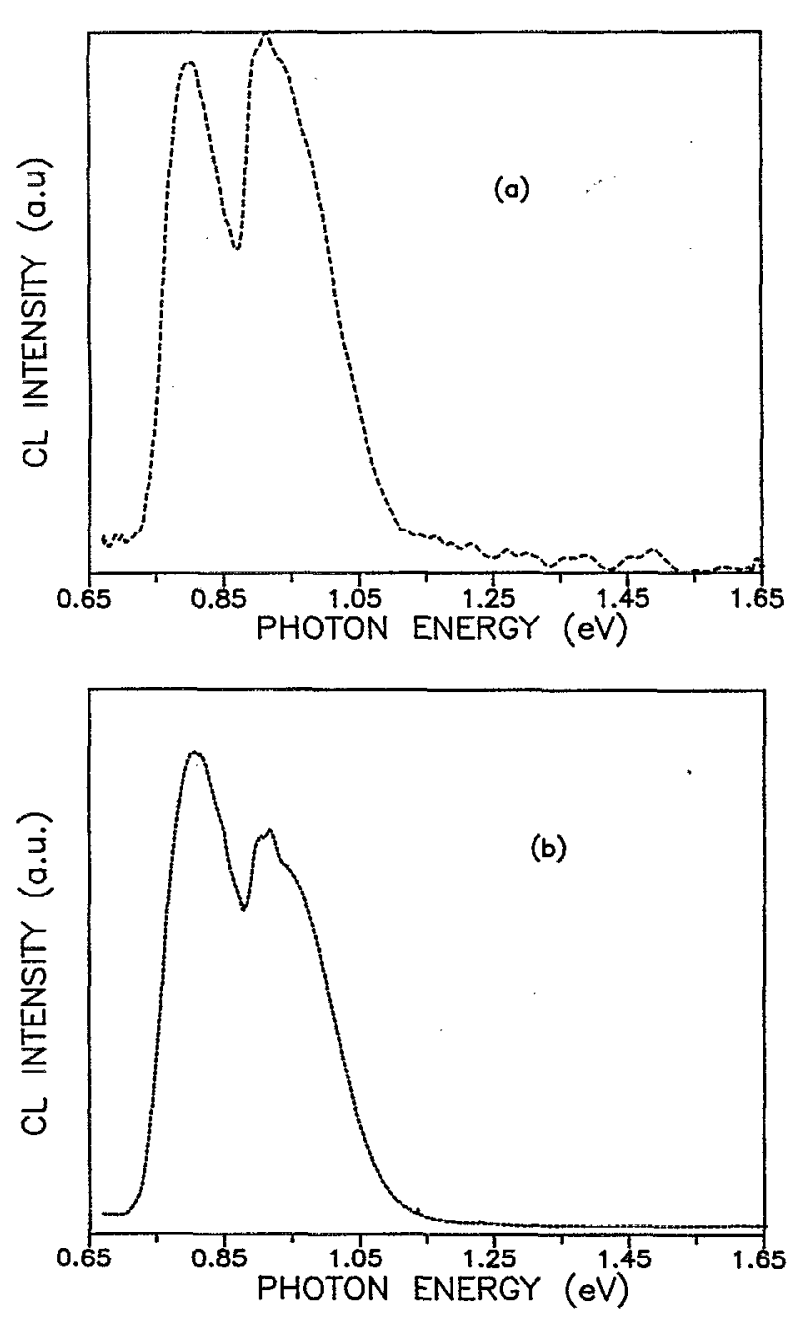

FIG. 3. CL spectra recorded under defocusing conditions of annealed samples: (a) CdTe:Ge1 and (b) CdTe:Ge2.

cause a $\mathrm{Ge}$ impurity situated in $\mathrm{Cd}$ sites reduces the $V_{\mathrm{Cd}}$ concentration and consequently decreases the probability of A-center formation. A similar effect has been previously observed in the V-doped samples ${ }^{8}$ while In doping enhances the $A$-center component. ${ }^{16}$ The similarity of ionic radius of $\mathrm{Cd}(0.97 \AA)$ and $\mathrm{Ge}(0.93 \AA)$ would favor the filling of $V_{\mathrm{Cd}}$

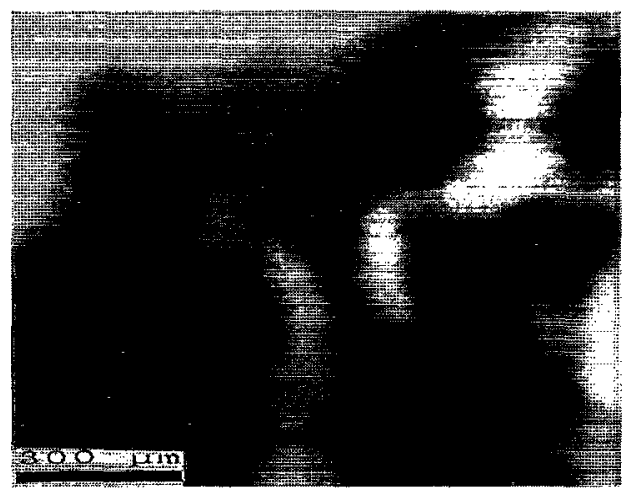

FIG. 4. Panchromatic CL image of annealed CdTe:Gel.

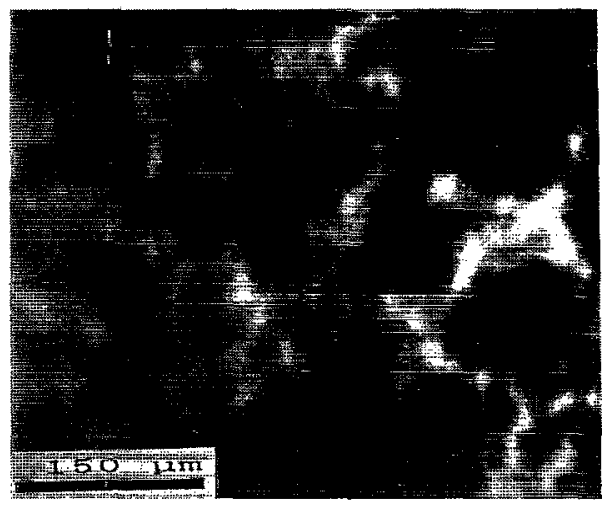

FIG. 5. Panchromatic CL image of as-grown CdTe:Ge2.

by $\mathrm{Ge}$ as compared with other impurities with a higher radius. The latter tend to form complexes with $V_{\mathrm{Cd}}$ rather than fill these vacancies. On the other hand, doping with atoms occupying Te sites in CdTe does not inhibit the appearance of the $1.40 \mathrm{eV}$ band. ${ }^{17}$ The appearance of a band-edge peak and the $1.40 \mathrm{eV}$ peak with a very low intensity in the CdTe:Ge2 samples may be due to the difference in the residual defect distribution in the crystals during the different growth runs.

In the low-energy region of the spectra, two bands centered, respectively, at about 0.91 and $0.81 \mathrm{eV}$ are observed in both doped and undoped samples. The bands are more intense in doped samples, suggesting the influence of $\mathrm{Ge}$ atoms. In particular, the $0.81 \mathrm{eV}$ band is always revealed as an intense emission in the spectra of doped samples while in undoped material is clearly revealed only under specific excitation conditions (defocused electron beam). The influence of $\mathrm{Ge}$ on the $0.81 \mathrm{eV}$ band is also apparent in its higher intensity in the CdTe:Ge2 crystals. The luminescence of $\mathrm{CdTe}$ in the $0.81 \mathrm{eV}$ region has been found to consist of two overlapping sub-bands with maxima at 0.81 and $0.72 \mathrm{eV}$, respectively. ${ }^{14,15}$ Takebe et al. ${ }^{18}$ characterized deep levels in CdTe by a photocapacitance technique, and deep level transient spectroscopy and concluded that a center that can emit photons of $0.75 \mathrm{eV}$ includes Cd vacancies or an impurity, as $\mathrm{Si}$ in Cd sites, whose solubility or stable site in the lattice depends on $\mathrm{Cd}$ vapor pressure. Emission in the $0.81 \mathrm{eV}$ region in our undoped samples could be due, according with the results of Ref. 17, to the Si residual impurity in CdTe. The observed enhancement of the $0.81 \mathrm{eV}$ band in the Gedoped samples can be explained by the fact that Ge plays a similar role as $\mathrm{Si}$ in the $0.81 \mathrm{eV}$ emission. The band peaked at about $0.91 \mathrm{eV}$ which is present in both kinds of samples but more readily observed in Ge-doped crystals, can have a similar origin as the $0.81 \mathrm{eV}$ emission. In a study of deep levels in CdTe by EPR techniques ${ }^{19}$ a level at $0.95 \mathrm{eV}$ below the conduction-band edge was assigned to Ge dopant.

$\mathrm{CL}$ images show that centers emitting in the $0.70-0.91$ $\mathrm{eV}$ range, which are responsible for the luminescence in $\mathrm{Ge}-$ doped samples, are preferentially distributed in the subboundaries. The grainy structure of sub-boundaries in the CL images has been observed in other doped CdTe crystals ${ }^{8}$ and indicates an inhomogeneous distribution of luminescence 
centers along the sub-boundaries. However, on increasing the $\mathrm{Ge}$ atom concentration, these centers become more concentrated at the sub-boundaries.

The results of annealing treatment support the possibility that $\mathrm{Ge}$ is involved in the emission at 0.91 and $0.81 \mathrm{eV}$. Annealing the undoped samples causes the increase of a band at $1.08 \mathrm{cV}$ and the suppression of emission at lower energies. This $1.08 \mathrm{eV}$ band has previously been reported in annealed undoped $\mathrm{CdTe}^{8}$ and is attributed to the presence of Te vacancies. Annealing the Ge-doped samples causes the increase of the 0.81 and $0.91 \mathrm{eV}$ bands as depicted in Fig. 3. During annealing, cadmium vacancies are generated and the probability of formation of complex centers involving $\mathrm{Ge}$ in $\mathrm{Cd}$ sites is enhanced. The diffuse appearance of luminescence in $C L$ images of annealed samples indicates the redistribution and formation of luminescent centers during annealing related to vacancy generation and impurity diffusion processes.

\section{CONCLUSIONS}

Like $\mathrm{V}$ atoms, Ge plays a similar role of compensating $C d$ vacancies and reduces the probability of $A$-center formation in CdTe crystals. Appearance of $0.81 \mathrm{eV}$ emission in CdTe crystals can be influenced very much by Ge doping. Postgrowth thermal annealing of the Ge-doped CdTe causes the formation of $\mathrm{Cd}$ and $\mathrm{Te}$ vacancies and enhances the probability of formation of complex centers involving $\mathrm{Ge}$ in $\mathrm{Cd}$ sites.

In undoped CdTe, either annealed or unannealed, the contribution of 0.91 and $0.81 \mathrm{eV}$ emission is minor to the total luminescence integrated intensity. On the contrary, in Ge-doped CdTe crystals those levels are a much more important radiative pathway because the near-band-gap radiative transitions are greatly reduced.

\section{ACKNOWLEDGMENTS}

Two of the authors (U. P. and N. V. S.) thank Spanish MEC for the postdoctoral research grants. The work has been supported by the DGICYT (PB90-1017 and PB93-1256) projects.

${ }^{1}$ R. B. Bylsma, P. M. Bridgenbaugh, D. H. Olson, and A. M. Glass, Appl. Phys. Lett. 51, 889 (1987).

${ }^{2}$ A. Partovi, J. Millerd, E. Garmire, M. Ziari, W. H. Steier, S. B. Trivedi, and M. B. Klein, Appl. Phys. Lett. 57, 846 (1990).

${ }^{3}$ N. V. Sochinskii, V. N. Babentsov, N. I. Tarbaev, M. D. Serrano, and E. Diéguez, Mater. Res. Bull. 28, 1061 (1993) and references therein.

${ }^{4}$ N. V. Sochinskii, M. D. Serrano, V. N. Babentsov, N. I. Tarbaev, J. Garrido, and E. Dieéguez, Semicond. Sci. Technol. (in press).

${ }^{5}$ C. Eiche, D. Maier, D. Sinerius, J. Weese, K. W. Benz, and J. Honerkamp, J. Appl. Phys. 74, 6667 (1993).

${ }^{6}$ V. P. Zayachkivskii, A. V. Savitskii, E. S. Nikonyuk, M. S. Kitsa, and V. V. Matlak, Sov. Phys. Semicond. 8, 675 (1974).

${ }^{7}$ H. J. Von Bardeleben, J. C. Launay, and V. Mazoyer, Appl. Phys. Lett. 63, 1140 (1993).

${ }^{8}$ U. Pal, J. Piqueras, P. Fernández, M. D. Serrano, and E. Diéguez, J. Appl. Phys. 76, 3720 (1994).

${ }^{9}$ V. V. Matlak, E. S. Nikonyuk, A. V. Savitskii, and K. D. Tovstyuk, Sov. Phys. Semicond. 6, 1760 (1973).

${ }^{10}$ C. Scharager, P. Siffert, P. Hoschl, P. Moravec, and M. Vanecek, Phys. Status Solidi A 66, 87 (1981).

${ }^{11}$ F. Domínguez-Adame, J. Piqueras, and P. Fernández, Appl. Phys. Lett. 58, 257 (1991).

${ }^{12}$ H. C. Casey and J. S. Jayson, J. Appl. Phys. 42, 2774 (1971).

${ }^{13}$ U. Pal, P. Fernández, J. Piqueras, M. D. Serrano, and E. Diéguez, Am. Inst. Phys. Conf. Ser. No. 135, 177 (1994).

${ }^{14}$ J. Krustok, A. Loo, and T. Piibe, J. Phys. Chem. Solids 52, 1037 (1991).

${ }^{15}$ Yu. I. Krustak, T. E. Piibe, and A. E. Lyo, Sov. Phys. Semicond. 25, 759 (1991).

${ }^{16}$ C. E. Barnes and K. Zanio, J. Appl. Phys. 46, 3959 (1975).

${ }^{17}$ U. Pal, P. Fernández, and J. Piqueras, Mater. Lett. (in press).

${ }^{18} \mathrm{~T}$. Takebe, J. Saraie, and II. Matsunami, J. Appl. Phys. 53, 457 (1992).

${ }^{19}$ W. Jantsch and G. Hendorfer, J. Cryst. Growth 101, 404 (1990). 
Journal of Applied Physics is copyrighted by the American Institute of Physics (AIP). Redistribution of journal material is subject to the AIP online journal license and/or AIP copyright. For more information, see http://ojps.aip.org/japo/japcr/jsp

Copyright of Journal of Applied Physics is the property of American Institute of Physics and its content may not be copied or emailed to multiple sites or posted to a listserv without the copyright holder's express written permission. However, users may print, download, or email articles for individual use. 
Journal of Applied Physics is copyrighted by the American Institute of Physics (AIP). Redistribution of journal material is subject to the AIP online journal license and/or AIP copyright. For more information, see http://ojps.aip.org/japo/japcr/jsp 